\title{
Effect of surface treatments on the bond repair strength of resin composite to different artificial teeth
}

\author{
Amanda Maria de Oliveira Dal Piva, João Paulo Mendes Tribst', Paula Carolina Komori de Carvalho, \\ Eduardo Shigueyuki Uemura, Tarcisio José de Arruda Paes Junior and Alexandre Luiz Souto Borges
}

*Correspondence:

joao.tribst@ict.unesp.br; joao.

tribst@gmail.com

Post-Graduate Program

in Restorative Dentistry

(Prosthodontic), Department

of Dental Materials

and Prosthodontics, São

Paulo State University

(Unesp/SJC), Engenheiro

Francisco José Longo

Avenue, 777, São José dos

Campos, SP 12245-000, Brazil

\begin{abstract}
The purpose of this study was investigate the influence of different surface treatments on the shear bond strength of two different type of artificial resin teeth repaired with composite resin. Fifteen (15) artificial teeth of each material (CR-composite resin and AR-acrylic resin) were divided into four parts and then embedded in acrylic resin. After, the teeth were separated into eight groups according to the surface treatments prior to the repair: control group (c), adhesive application (a), sandblasting (S) and sandblasting followed by adhesive application (Sa). Next, a composite resin cylinder $(\varnothing=0.95 \mathrm{~mm}$ e $\mathrm{h}=2 \mathrm{~mm}$ ) simulating a repair was built onto each surface. The specimens were submitted to a microshear bond test after $24 \mathrm{~h}$, using a universal testing machine $(1 \mathrm{~mm} / \mathrm{min}, 50 \mathrm{kgf})$ until fracture. The data was subjected to two-way analysis of variance (ANOVA) and Tukey test, with a significance level of $5 \%$. ANOVA showed statistical difference for the interaction artificial teeth material* surface treatment $(p=0.001)$. CR teeth $(29.79 \pm 11.54 \mathrm{MPa})$ showed higher bond strength mean values than AR (18.48 $\pm 9.73 \mathrm{MPa}$ ). Regardless the artificial teeth material, Sa $(36.92 \pm 6.16 \mathrm{MPa})$ treatment showed the higher bond strength values. The highest bond strength value was found in CRSa $(45.93 \pm 7.13 \mathrm{MPa})$ and the lowest was found in ARc (5.38 $\pm 0.90 \mathrm{MPa})$. Based on the results, tooth material should be taken in account in order to choose the best surface treatment and achieve suitable bond strength values when a repair is necessary. For artificial teeth in acrylic resin, applying an adhesive system is the best procedure, with or without sandblasting the alumina particles. However, for artificial teeth in composite resin, an association of sandblasting followed by applying an adhesive system showed more promising bond strength values.
\end{abstract}

Keywords: Surface treatment, Shear bond strength, Composite resin, Acrylic resin, Artificial teeth

\section{Introduction}

Full arch prosthesis is one alternative to rehabilitate edentulous patients. This prosthesis consists of artificial teeth mounted on a mucus supported acrylic resin base with the purpose to restore aesthetics, phonetics and mastication [1]. During chewing, the stresses induced in the denture may cause injury to the support tissue, if equilibrium conditions suitable for occlusal adjustment are not created [2]. The most common material used for artificial teeth is acrylic resin with acceptable mechanical properties and 
durability [3]. Acrylic resin is easily adjusted and concentrates less stress compared to ceramic teeth [4]. Furthermore, there is a chemical interaction between the resin base and artificial teeth [3]. Regarding disadvantages, acrylic resin artificial teeth exhibit often-occlusal wear, which leads to decreased masticatory efficiency and loss of vertical dimension [5].They also present clinical problems, as they suffer remolding of worn occlusal surfaces in denture teeth $[5,6]$, and fractures or debonding from the prosthesis base [7].

In spite of this, artificial teeth in composite resin have been used with the purpose of improving aesthetics and to enable the repair of worn occlusal surfaces with composite resin $[5,8]$. Repairing the occlusal surfaces from posterior artificial teeth with composite resin allows for controlling the vertical occlusion dimension and the maintenance of occlusal contacts. The possibility to repair the prosthesis in the clinic eliminates the need for time-consuming procedures, thus reducing costs and prolonging the prosthesis lifetime [8].

The success of these procedures mainly depends on the composite resin adhesion to the artificial teeth [7]. Various methods have been reported to improve the reactivity of highly converted composites; these methods include acid etching [9], air abrasion [10] and the use of adhesives [11]. There is no consensus on the results obtained with the different procedures. Therefore, this study aimed to analyze the effect of surface treatment on the microshear bond strength between two type of artificial teeth and a composite resin repair. The study hypothesis was that there would be no influence of the artificial teeth material and surface treatments on the bond strength between composite resin and repaired teeth.

\section{Materials and methods}

Thirty (30) artificial molars were selected and divided into two groups $(\mathrm{n}=15)$ : Group CR-composite resin artificial teeth (Soluut, KotaImports, São Paulo, SP, Brazil) and Group AR-Acrylic Resin artificial teeth (Yamahachi New Ace; Yamahachi Dental Mfg., Co., Aichi Pref., Japan). All teeth occlusal portions were cut with a diamond blade under water-cooling (Isomet 1000, Buehler, Lake Bluff, IL, USA), and subjected to a polishing machine (Erios-Technical and Scientific Equipment Ltda, São Carlos, Brazil) with 600 grit sandpaper for regularizing and standardizing the surface roughness. After, each tooth was sectioned into 4 parts that were embedded in chemically activated acrylic resin (Jet-Classic, São Paulo, Brazil) prior to receive different surface treatments. The groups were randomly assigned according to the surface treatment: subgroup c-did not received any surface treatment; subgroup a-application of an adhesive system layer (Signum Connector, Heraeus Kulzer, GER) polymerized for $40 \mathrm{~s}$ as per the manufacturer's instructions (1200 $\mathrm{mW} / \mathrm{cm}^{2}$ - Radii Cal, SDI, Australia); subgroup S-sandblasting with $\mathrm{Al}_{2} \mathrm{O}_{3}$ particles $(50 \mu \mathrm{m})$ [12] for $10 \mathrm{~s}$ with a distance of $10 \mathrm{~mm}$ and a pressure of 2.8 bar; and subgroup $\mathrm{Sa}-$ sandblasting followed by an adhesive system application. The group's distribution is summarized in Table 1, and Fig. 1 shows a schematic illustration of the specimen preparation.

Next, composite resin (Venus, Heraeus Kulzer, GER) cylinders (0.95 mm diameter and $2.0 \mathrm{~mm}$ high) were prepared using a rubber mold (Lamedid-an infusion device intravenous number $21 \mathrm{G}$ ) on the surface of each sample and light cured for 
Table 1 Group distribution, descriptive statistical analysis (bond strength mean values in MPa and standard deviation) and Tukey test for the interaction "artificial teeth material*surface treatment"

\begin{tabular}{lllr}
\hline Groups & Artificial teeth material & Surface treatment & Mean \pm Std \\
\hline ARc & Acrylic resin & No treatment & $5.38 \pm 0.89^{\mathrm{a}}$ \\
$\mathrm{CRC}$ & Composite resin & & $19.41 \pm 4.62^{\mathrm{bc}}$ \\
ARa & Acrylic resin & Adhesive system application & $23.76 \pm 3.88^{\mathrm{cd}}$ \\
$\mathrm{CRa}$ & Composite resin & & $28.40 \pm 6.22^{\mathrm{d}}$ \\
ARS & Acrylic resin & Sandblasting with $\mathrm{Al}_{2} \mathrm{O}_{3}$ particles & $17.23 \pm 5.64^{\mathrm{b}}$ \\
$\mathrm{CRS}$ & Composite resin & & $25.39 \pm 5.75^{\mathrm{cd}}$ \\
ARSa & Acrylic resin & Sandblasting and adhesive system & $27.91 \pm 6.27^{\mathrm{d}}$ \\
CRSa & Composite resin & application & $45.93 \pm 7.13^{\mathrm{e}}$ \\
\hline
\end{tabular}

Same superscript letters are not significantly different $(p<0.05)$

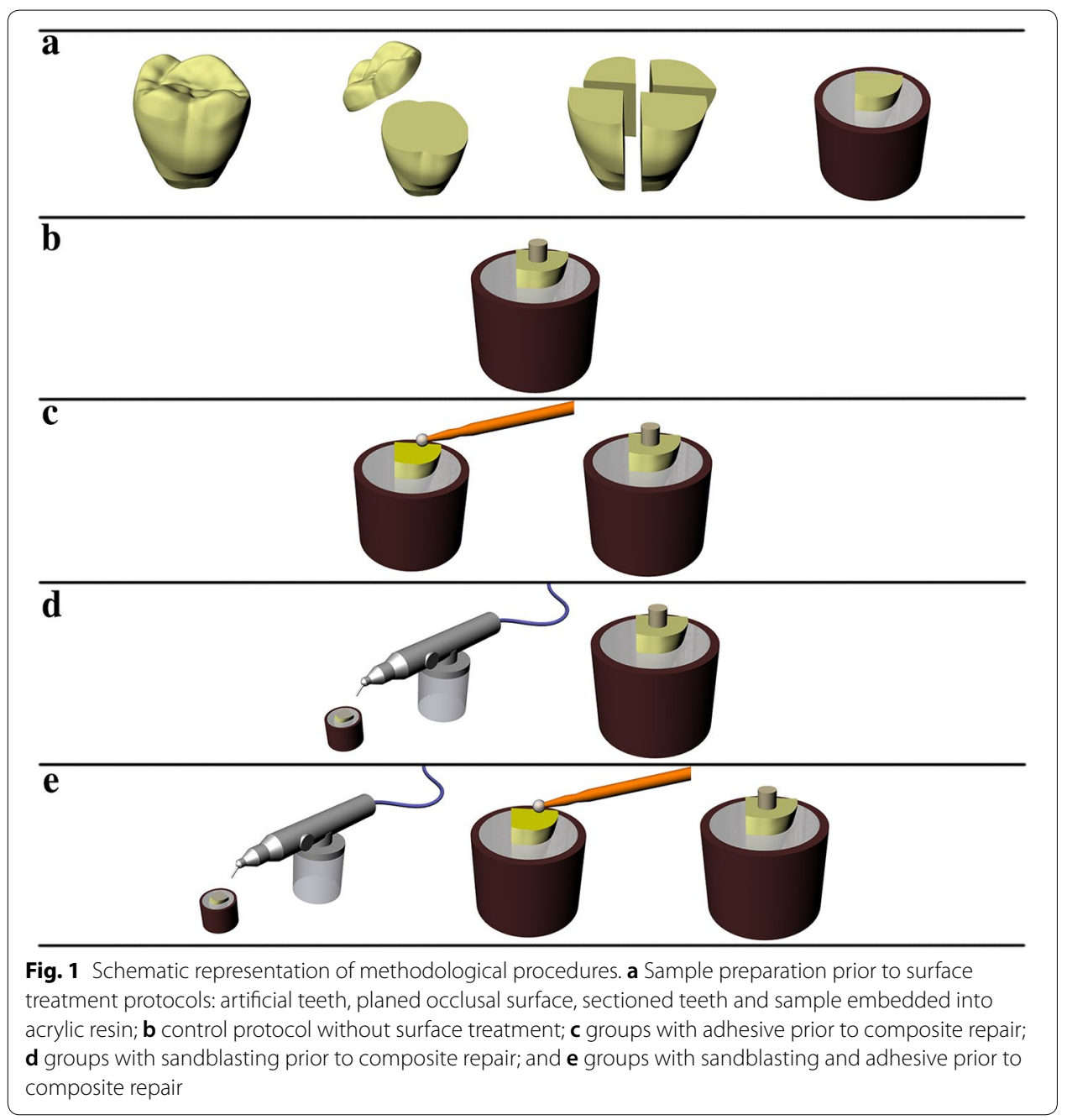

$40 \mathrm{~s}\left(1200 \mathrm{~mW} / \mathrm{cm}^{2}\right.$-Radii Cal, SDI, Australia) [13]. The molds were gently removed and the samples were stored in distilled water at $37^{\circ} \mathrm{C}$ for $24 \mathrm{~h}$ before the mechanical test. The microshear bond strength test was performed in a universal testing machine (DL1000, EMIC, São José dos Campos, SP, Brazil) and the load was applied at the 
cylinder base by a steel wire $(0.2 \mathrm{~mm}$ in diameter $)$ at a speed of $0.5 \mathrm{~mm} / \mathrm{min}$ and a load cell of $50 \mathrm{kgf}$ until specimen fracture $[14,15]$. Bond strength mean values were calculated by the formula: $\mathrm{R}=\mathrm{F} / \mathrm{A}$, where $\mathrm{R}$ corresponds to the adhesive strength (MPa); F corresponds to the maximum load $(\mathrm{N})$; and A corresponds to the adhesive area $\left(1.41 \mathrm{~mm}^{2}\right)$, as calculated by the formula: $2 \pi \mathrm{r}^{2}$. Statistical analysis was performed using two-way analysis of variance (ANOVA) according to the factors "artificial teeth material" and "surface treatment". The Tukey test was performed for group comparison, while all tests considered a significance value of $5 \%$ [15].

\section{Results}

Two-way ANOVA showed statistically significant differences for both isolate factors and for their interaction, with $\mathrm{p}$ value $=0.001$. Independent of the surface treatment, thus considering only the factor "artificial teeth material", teeth in composite resin $(29.79 \pm 11.54)$ showed higher bond strength values than teeth in acrylic resin (18.48 \pm 9.73$)$. And, regarding the "surface treatment" factor independent of the artificial teeth material, the bond strength values increased in the ratio: no treatment $\quad(12.40 \pm 3.38)^{\mathrm{d}}<$ sandblasting $\quad(21.31 \pm 4.82)^{\mathrm{c}}<$ adhesive system application $(26.08 \pm 5.74)^{\mathrm{b}}<$ sandblasting followed by adhesive system application $(36.92 \pm 6.16)^{\mathrm{a}}$. Table 1 summarizes the descriptive statistical analysis and the multiple comparison between groups. The repaired composite resin artificial teeth showed the highest bond strength mean values when treated with sandblasting and adhesive system application. While for acrylic resin teeth, the application of the adhesive system significantly improved the mean bond strength values, preceded or not by sandblasting.

\section{Discussion}

The results showed that composite resin teeth presented higher mean bond strength values than acrylic resin teeth during the repair of occlusal surfaces with composite resin. Also, the sandblasting surface treatment followed by applying an adhesive improved these results for artificial teeth in composite resin, thus rejecting the study hypothesis.

In order to achieve durable bond strength between composite resin and artificial teeth, it is essential to know the effects of different surface treatments that can modify the interaction between these materials [8]. Shear, microshear, tensile and microtensile tests can be used to evaluate bond strength. Despite the limitations of the shear test, sample standardization and easy preparation, as well as suitable laboratory equipment make this test a commonly used methodology to determine the adhesive strength of dental materials $[12,15]$.

Artificial teeth in composite resin are commonly used due to the physical composite resin properties such as abrasion resistance, color stability, lower water sorption and chemical bonding to acrylic resin. According to the results, composite resin repair adhesion is not effective without any surface treatment, regardless of the material used in the artificial teeth. Results show that, for composite resin teeth, it is necessary to perform mechanical retention to achieve more suitable bond strength values [4], allowing the adhesive and composite resin repair to penetrate into the surface micro irregularities and yield mechanical bond strength $[8,16-18]$. The sandblasting procedure increased the mean bond strength values compared to no surface treatment. And, when followed 
by the application of the adhesive system, the higher bond strength values were achieved. A bonding agent has long been used with composite resin in restorative dentistry [12]. It improves surface wettability by causing the resin infiltrate into microscopic surface irregularities $[8,17]$. Some studies have shown that a bonding agent was essential for achieving adequate bond strength between light-activated and polymerized resin $[5,8$, 17]. For AR teeth, higher bond strength values were found when an adhesive system was applied, regardless of sandblasting. This mean values were similar to the repair bond strength of CR treated only with adhesive system application. Sandblasting was required to increase the tooth surface roughness and therefore to verify if its presence would benefit the adhesion between the repair and the tooth. Likewise, the adhesive itself for this situation was chosen to test its effectiveness in enhancing bond strength. Furthermore, teeth in composite resin and acrylic resin were selected because they are the most common artificial teeth used. The combination of a rougher surface/sandblasted surface and bond agent application significantly improved the shear bond strength between the repair and the tooth in composite resin. Nevertheless, this protocol showed similar result to only applying bond agent for acrylic resin teeth $[7,19]$.

Santos et al. [20] evaluated the influence of adhesives on the bond strength between artificial teeth and a thermally activated acrylic resin. The authors also associated a sandblasting protocol of aluminum oxide particles with the bond agents. The results showed that the use of adhesives significantly affected the tooth/prosthesis base union. In the present study, the bond strength between tooth and composite resin (repair) was tested. Regardless of tooth material, the presence of the bond agent was always beneficial.

It is important to notice that these results should be extrapolated with care since this was an in vitro study, with no variables found in the oral medium such as temperature and $\mathrm{pH}$ variations, as well as no aging methodology that could test the groups bond strength in the long term. However, based on these findings, the present study led to developing a protocol for more effective surface treatment, increasing the bond strength of artificial teeth repaired with a composite resin.

\section{Conclusion}

Notwithstanding the limitations of this study, the following conclusions can be made: (i) tooth material should be taken in account in order to choose the best surface treatment and achieve suitable bond strength values when a repair is necessary; (ii) for artificial teeth in acrylic resin, applying an adhesive system is the best procedure, with or without sandblasting the alumina particles; (iii) for artificial teeth in composite resin, an association of sandblasting followed by applying an adhesive system showed more promising bond strength values.

\section{Clinical significance}

The damaged artificial teeth material should be considered to determine the suitable surface treatment to promote acceptable bond strength values to a repair using composite resin. 


\section{Abbreviations}

CR: composite resin; AR: acrylic resin; c: control group; a: adhesive application; S: sandblasting; Sa: sandblasting followed by adhesive application; $\varnothing$ : diameter; $h$ : high; ANOVA: one-way analysis of variance; $\mathrm{Al}_{2} \mathrm{O}_{3}$ : aluminium oxide; ISO: International Organization for Standardization.

\section{Authors' contributions}

AMdeODP participated on the concepts, design, definition of intellectual content, literature search, data acquisition, data analysis, manuscript preparation, manuscript editing and manuscript review; JPMT participated on the concepts, design, definition of intellectual content, literature search, data acquisition, data analysis and manuscript review; PCKdeC participated on the concepts, design, data acquisition, data analysis and manuscript preparation; ESU participated on the concepts, design, definition of intellectual content, data analysis and manuscript editing; TJdeAPJ and ALSB participated on the concepts, design, literature search, data acquisition, data analysis and manuscript review. All authors read and approved the final manuscript.

\section{Acknowledgements}

None.

\section{Competing interests}

The authors declare that they have no competing interests.

\section{Availability of data and materials}

The datasets used and/or analysed during the current study are available from the corresponding author on reasonable request.

\section{Funding}

None.

\section{Publisher's Note}

Springer Nature remains neutral with regard to jurisdictional claims in published maps and institutional affiliations.

Received: 11 September 2018 Accepted: 20 November 2018

Published online: 28 November 2018

\section{References}

1. Borges AL, Borges AB, Uemura ES, Paes-Júnior TJ, Tango RN, de Araújo JE, Kimpara ET. Evaluation of a new intraoral paralleling device for creating guiding planes: a pilot study. J Contemp Dent Pract. 2010;11:E065-72.

2. Hafezeqoran A, Koodaryan R, Noorazar SG, Hajialilue-Bonab M, Hassanzadeh M, Yasamineh N. Evaluation of strain in mandibular denture-supporting area in three different occlusal schemes during jaw movements. J Dent Res Dent Clin Dent Prospects. 2018;12:18-25.

3. Neppelenbroek KH, Kuroishi E, Hotta J, Marques VR, Moffa EB, Soares S, Urban VM. Surface properties of multilayered, acrylic resin artificial teeth after immersion in staining beverages. J Appl Oral Sci. 2015;23:376-82.

4. Dal Piva AMO, Tribst JPM, Borges ALS, Souza ROAE, Bottino MA. CAD-FEA modeling and analysis of different full crown monolithic restorations. Dent Mater. 2018:34:1342-50.

5. Ghazal M, Kern M. Wear of denture teeth and their human enamel antagonists. Quintessence Int. 2010;41:157-63.

6. Preis V, Hahnel S, Behr M, Rosentritt M. Contact wear of artificial denture teeth. J Prosthodont Res. 2008;62:252-7.

7. Andrade de Freitas SL, Brandt WC, Miranda ME, Vitti RP. Effect of thermocycling, teeth, and polymerization methods on bond strength teeth-denture base. Int J Dent. 2018;2018:2374327.

8. Chatterjee N, Gupta TK, Banerjee A. A study on effect of surface treatments on the shear bond strength between composite resin and acrylic resin denture teeth. J Indian Prosthodont Soc. 2011;11:20-5.

9. Bahari M, Savadi-Oskoee S, Kimyai S, Savadi-Oskoee A, Abbasi F. Effects of different etching strategies on the microtensile repair bond strength of beautifil II giomer material. J Clin Exp Dent. 2018;10:e732-8.

10. Boyer DB, Chan KC, Torney DL. The strength of multilayer and repaired composite resin. J Prosthet Dent. 1978;39:63-7.

11. Irmak O, Celiksoz O, Yilmaz B, Yaman BC. Adhesive system affects repair bond strength of resin composite. J Istanb Univ Fac Dent. 2017:51:25-31.

12. Araújo AMM, Januário ABN, Moura DMD, Tribst JPM, Özcan M, Souza ROA. Can the application of multi-mode adhesive be a substitute to silicatized/silanized Y-TZP ceramics? Braz Dent J. 2018;29:1-7.

13. Massotti TG, Barcellos DC, Petrucelli N, Tribst JP, Gonçalves SEP. Analysis of flexural strength of composite resins polymerized by 2nd and 3rd generation leds. Braz Dent Sci. 2015;18:67-74.

14. Shimada Y, Kikushima D, Tagami J. Micro-shear bond strength of resin-bonding systems to cervical enamel. Am J. Dent. 2002;15:373-7.

15. Dal Piva AMO, Tribst JPM, Bottino MA. Evaluation of shear bond strength and shear stress on zirconia reinforced lithium silicate and high translucency zirconia. J Oral Res. 2018;7:30-6.

16. Muhsin SA. Bond strength of repaired acrylic denture teeth using visible light cure composite resin. Open Dent J. 2017;11:57-64. 
17. Tribst JPM, Anami LC, Özcan M, Bottino MA, Melo RM, Saavedra GSFA. Self-etching primers vs acid conditioning: impact on bond strength between ceramics and resin cement. Oper Dent. 2018;43:372-9. https://doi. org/10.2341/16-348-L.

18. Barcellos DC, Pucci CR, Torres CR, Goto EH, Inocencio AC. Effects of resinous monomers used in restorative dental modeling on the cohesive strength of composite resin. J Adhes Dent. 2008;10:351-4.

19. Lucena-Martin C, Gonzalez-Lopez S, de Mondelo LMNR. The effect of various surface treatments and bonding agents on the repaired strength of heat-treated composites. J Prost Dent. 2001;86:481-8.

20. Santos EM, Saavedra GSFA, Nesser MP. Effect of adhesives on the joint between artificial teeth and heat-curing resins. Cienc Odontol Bras. 2005;8:47-54.

Submit your manuscript to a SpringerOpen ${ }^{\circ}$ journal and benefit from:

- Convenient online submission

- Rigorous peer review

- Open access: articles freely available online

- High visibility within the field

- Retaining the copyright to your article

Submit your next manuscript at $>$ springeropen.com 